\title{
Research Article \\ Surface Microstructure of Nanoaluminized CoCrAlY Coating Irradiated by HCPEB
}

\author{
Zhiyong Han, Jian Han, and Zhenzhu Jing \\ Tianjin Key Laboratory for Civil Aircraft Airworthiness and Maintenance, Civil Aviation University of China, Tianjin 300300, China \\ Correspondence should be addressed to Zhiyong Han; zyhan@cauc.edu.cn
}

Received 6 January 2016; Revised 16 March 2016; Accepted 12 April 2016

Academic Editor: Albano Cavaleiro

Copyright (C) 2016 Zhiyong Han et al. This is an open access article distributed under the Creative Commons Attribution License, which permits unrestricted use, distribution, and reproduction in any medium, provided the original work is properly cited.

\begin{abstract}
A thermal sprayed CoCrAlY coating was prepared by air plasma spray on the surface of Ni-based superalloy GH4169; then, a nanoscale aluminum film was deposited with electron beam vacuum deposition on it. The coatings irradiated by high-current pulsed electron beam were investigated. After HCPEB treatment, the Al film was remelted into the bond coat. XRD result shows that $\mathrm{Al}$ and $\mathrm{Al}_{2} \mathrm{O}_{3}$ phase were recorded in the irradiated and aluminized coatings, while Co-based oxides which originally existed in the initial samples disappeared. Microstructure observations reveal that the original coating with porosity, cavities, and inclusions was significantly changed after HCPEB treatment as compact appearance of interconnected bulged nodules. Moreover, the grains on the irradiated coating were very refined and homogeneously dispersed on the surface, which could effectively inhibit the corrosive gases and improve the coating oxidation resistance.
\end{abstract}

\section{Introduction}

With the rapid development of aerospace industry, hundreds of different types of coatings have been investigated to protect structural engineering materials from corrosion, wear, and erosion and to provide lubrication and thermal insulation [1-3]. Therefore, thermal barrier coatings (TBCs) have been extensively used for aircraft and industrial gasturbine engines in the most demanding high-temperature environment because of the most complex structure and the excellent performance [4]. TBCs, typically, consist of the ceramic top coat (TC) (YSZ, $\mathrm{ZrO}_{2}-7-8 \mathrm{wt} \% \mathrm{Y}_{2} \mathrm{O}_{3}$ ) and the metallic bond coat (BC) (MCrAlY, where $\mathrm{M}=\mathrm{Ni}$ and/or Co) [5-7]. BC, the important constituent of TBC systems, could enhance the adhesion of the ceramic thermal barrier layer to the substrate and also provide oxidation protection to the substrate metal. However, during high-temperature service, thermal barrier coating systems would be influenced greatly on the thermal cycling that ultimately results in the TBC failure by spallation of the TC [8-10]. The main reason is that the oxidation of metallic elements of MCrAlY takes place in the $\mathrm{BC}$ which generates the thermally growth oxide (TGO). The formation and growth of TGO would lead to the maximum stress at the interface between TC and BC, which is the main factor in the failure of TBCs due to uncontrolled growth of TGO during thermal exposure in air [11, 12].

During the formation of TGO, mixed oxides of $\mathrm{Cr}$ and Co elements in the $\mathrm{BC}$ usually appear after the selective oxidation of $\mathrm{Al}$ element; then, an $\mathrm{Al}$-depleted zone would be present beneath the oxide layer, which could shorten the service time of TBCs $[13,14]$. Generally, the ideal TGO was formed as a slow- and steady-growing alpha-alumina oxide $\left(\alpha-\mathrm{Al}_{2} \mathrm{O}_{3}\right)$ which could provide an excellent diffusion barrier of oxygen and suppress further oxidation of $\mathrm{BC}$ [15]. Many researchers have investigated particularly the formation mechanisms of TGO to avoid the appearance of $\mathrm{Al}$ depletion [16, 17]. Consequently, through some modified methods to form the fine-grained structure and increase $\mathrm{Al}$ element concentration on the surface and subsurface of CoCrAlY coating, the selective oxidation of Al element could keep proceeding to avoid the formation of other oxides and improve the formation of $\alpha-\mathrm{Al}_{2} \mathrm{O}_{3}$ layer.

Electron beam vacuum deposition (EBVD) has been extensively used to prepare a certain number of films, such as $\mathrm{Al}-\mathrm{Mn}, \mathrm{Al}-\mathrm{Cr}$, and $\mathrm{TiO}_{2}$, because of their unique physical and chemical properties and technological applications including ultraviolet light absorbers and gas sensors [18-20]. Compared with the conventional electrochemical deposition of organic 
TABLE 1: Air plasma spraying parameters.

\begin{tabular}{lccccccc}
\hline Parameter & Voltage (V) & Current (A) $\begin{array}{c}\text { Powder feed rate } \\
(\mathrm{rmp})\end{array}$ & $\begin{array}{c}\text { Spray distance } \\
(\mathrm{mm})\end{array}$ & $\begin{array}{c}\text { Spray rate } \\
(\mathrm{mm} / \mathrm{s})\end{array}$ & $\begin{array}{c}\text { Primary gas } \\
(\mathrm{psi})\end{array}$ & $\begin{array}{c}\text { Secondary gas } \\
(\mathrm{psi})\end{array}$ & $\begin{array}{c}\text { Carrier gas } \\
(\mathrm{psi})\end{array}$ \\
\hline $\begin{array}{l}\text { CoCrAlY } \\
\text { coating }\end{array}$ & 38 & 750 & 2.5 & 85 & 450 & 60 & 110 \\
\hline
\end{tabular}

TABLE 2: Four kinds of experimental coating system.

\begin{tabular}{|c|c|c|c|c|}
\hline Coating & A & $\mathrm{B}$ & $\mathrm{C}$ & $\mathrm{D}$ \\
\hline $\begin{array}{l}\text { Preparation } \\
\text { procedure(s) }\end{array}$ & $\begin{array}{l}\text { As-sprayed CoCrAlY } \\
\text { coating }\end{array}$ & $\begin{array}{l}\text { As-sprayed CoCrAlY } \\
\text { coating }+20 \text { pulses }\end{array}$ & $\begin{array}{l}\text { As-sprayed CoCrAlY } \\
\text { coating }+\mathrm{Al}+10 \text { pulses }\end{array}$ & $\begin{array}{c}\text { As-sprayed CoCrAlY } \\
\text { coating }+\mathrm{Al}+20 \text { pulses }\end{array}$ \\
\hline
\end{tabular}

solvent and molten salt systems, EBVD has the advantages of high purity, less pollution, and good compactness [19]. In particular, many researchers have investigated in detail characteristics of pure Al film deposited by EBVD [21, 22]. Wang and Meng investigated the surface morphology, structure, adhesion, and corrosion resistance of $\mathrm{Al}$ and AlMn films deposited onto carbon steel by EBVD [21]. The deposited $\mathrm{Al}$ and $\mathrm{Al}-\mathrm{Mn}$ films are smooth, compact, and uniform. The corrosion resistance of $\mathrm{Al}$ film in $3.5 \% \mathrm{NaCl}$ solution increases with the film thickness and evaporation rate. Therefore, it is reasonable to deposit pure $\mathrm{Al}$ film by the way of EBVD on the surface of CoCrAlY coating.

It is well known that high-current pulsed electron beam (HCPEB) has been proved to be a powerful tool to modify surface microstructure and performance of materials recently, which has the comparative advantage of purer energy transport process and higher efficiency than the pulsed ion beam and laser beam [23-25]. During the transient irradiation process, a high electron beam energy $\left(10^{8}-\right.$ $10^{9} \mathrm{~W} / \mathrm{cm}^{2}$ ) is instantly deposited in a thin layer to form the affected zone with extremely high-temperature gradient [26]. There are lots of physical processes, which are heating, melting followed by rapid solidification, surface smoothing, and finishing as well as evaporation condensation, on the surface of coating after irradiation. Currently, numerous researchers have studied surface modification of different materials after HCPEB irradiation. Hao et al. found that the coarse surface of arc-sprayed $\mathrm{FeCrAl}$ coating was changed as discrete bulged nodules with smooth and compact appearance while the high-temperature corrosion resistance got worse after irradiation [27]. Cai et al. investigated the thermal sprayed YSZ coatings subjected to HCPEB and found that the very fine grains formed on the surface and high-temperature oxidation resistance was significantly improved after irradiation [26].

In this paper, a nanoscaled $\mathrm{Al}$ film was deposited on the thermal sprayed CoCrAlY coating with EBVD technique. With that, the coatings were subjected to a HCPEB irradiation process. The modified microstructure and surface roughness were characterized with an attempt to observe the effect of remelted surface with $\mathrm{Al}$ and comprehend the influence of $\mathrm{Al}$ depletion after HCPEB irradiation.

\section{Experimental}

Ni-based superalloy GH4169 (Cr 19.62, Fe 17.75, Nb + Ta 5.08, Mo 3.03, Ti 1.08, Al 0.58, Si 0.17, and Ni balance, wt\%) used as the substrate was cut into rectangular specimens of approximately $12 \times 8 \times 2 \mathrm{~mm}$. Co-23Cr-13Al- $0.5 \mathrm{Y}$ powder of size $5 \sim 50 \mu \mathrm{m}$ was used for the bond coating. To eliminate the residual oil contamination and surface oxides, all of the substrate materials were blasted by 60 -mesh white corundum using 8070P-B type blasting machine before deposition, which could obtain the required surface roughness for coating adhesion. After that, CoCrAlY powder was deposited on the substrate using Praxair 3710 type APS equipment. Corresponding spraying parameters are shown in Table 1. The coating thickness was about $200 \mu \mathrm{m}$.

High purity Al particles of size $\Phi 3 \times 3 \mathrm{~mm}$ were deposited on the CoCrAlY coating to generate $\mathrm{Al}$ film of $\sim 600 \mathrm{~nm}$ thickness by using DZS-500 type EBVD equipment. The EBVD deposition was carried out under the following parameters: vacuum $2.6 \times 10^{-6}$ Torr, electron beam gun voltage $8 \mathrm{KV}$, electron beam current $270 \mathrm{~mA}$, and the evaporation duration $80 \mathrm{~min}$. Then, the coated samples were irradiated at room temperature with 10 and 20 pulses using a Hope-1 type HCPEB source, respectively. The HCPEB irradiation was carried out under the following conditions: the electron energy $25 \mathrm{KeV}$, current pulse duration $1.5 \mu \mathrm{s}$, energy density $4 \mathrm{~J} / \mathrm{cm}^{2}$, and vacuum $3.8 \times 10^{-5}$ Torr. More details about the principle of HCPEB system are in [28].

The surface microstructure of the initial and irradiated samples was generally performed by using 1530VP type scanning electron microscope (SEM) and energy dispersive spectrometer (EDS). The phase structure of the coatings with and without $\mathrm{Al}$ film deposition before and after irradiation was examined using Rigaku D/max 2500/pc type X-ray diffraction (XRD) with CuK $\alpha$ radiation. Additionally, threedimensional laser scanning microscope (LSM) of type LEXTOLS4000 3D was carried out to obtain the surface roughness of the samples.

In order to distinguish the different coatings with and without $\mathrm{Al}$ films and before and after HCPEB irradiation and describe more detailed investigations of surface 


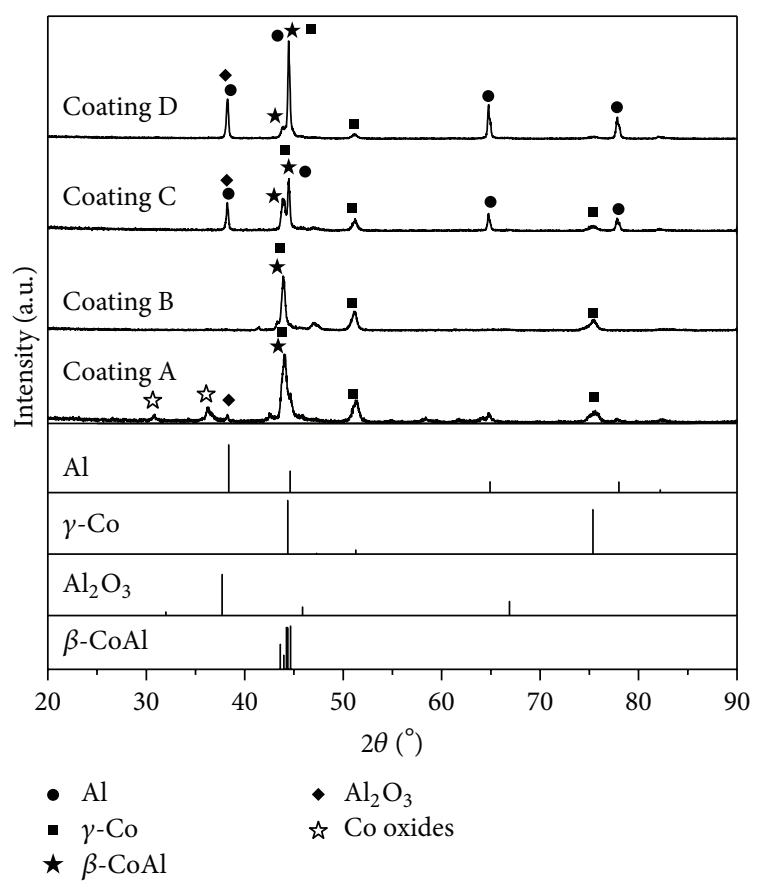

FIgURE 1: XRD patterns of coating A, B, C, and D.

microstructure, four kinds of coating systems were marked as $\mathrm{A}, \mathrm{B}, \mathrm{C}$, and $\mathrm{D}$, as shown in Table 2:

(1) Coating A represents the initial APS CoCrAlY coating.

(2) Coating B represents the APS CoCrAlY coating irradiated by HCPEB with 20 pulses.

(3) Coating $\mathrm{C}$ represents the nanoaluminized CoCrAlY coating irradiated by HCPEB with 10 pulses.

(4) Coating D represents the nanoaluminized CoCrAlY coating irradiated by HCPEB with 20 pulses.

\section{Results and Discussion}

The XRD results of the coatings are shown in Figure 1. Coating $\mathrm{A}$, the initial CoCrAlY coating, was composed mainly of $\beta$-CoAl and $\gamma$-Co solid solution phases. Meanwhile, a small amount of oxides, $\mathrm{Al}_{2} \mathrm{O}_{3}$ and Co-based oxides, was recorded on the surface of the initial coating. After 20pulse HCPEB irradiation, oxides disappeared on account of the special selective surface purification effect of HCPEB treatment [29]. Besides, coatings $\mathrm{C}$ and $\mathrm{D}$, after $\mathrm{Al}$ film deposition and HCPEB irradiation, consisted mostly of $\beta$ CoAl, $\gamma$-Co solid solution phases, $\mathrm{Al}$ phase, and little $\mathrm{Al}_{2} \mathrm{O}_{3}$ phase. Moreover, it was found that the content of $\mathrm{Al}$ increased while $\gamma$-Co was reduced with increasing the pulses of HCPEB irradiation correspondingly according to the comparison between coatings $\mathrm{C}$ and $\mathrm{D}$. Significantly, Al element was from the nanoscaled $\mathrm{Al}$ film on the CoCrAlY coating and the $\mathrm{CoAl}$ compound. Then, the superficial $\mathrm{Al}$ element was agglomerated with $\mathrm{O}$ element to form more stable $\mathrm{Al}_{2} \mathrm{O}_{3}$ phase. Accordingly, the peaks of $\mathrm{Al}_{2} \mathrm{O}_{3}$ phase were recorded.
It is worth noting that after HCPEB irradiation the XRD peaks were slightly shifted, indicating that residual stress existed in the coating owing to the rapid cooling [30]. Besides, the variation of chemical gradients and evaporation of $\mathrm{Al}$ element in the coating surface also could lead to the peaks shifting [31-33].

Figure 2 provides the morphology of coating A, the initial thermal sprayed CoCrAlY coating, which has the typical feature of APS coating. The surface was highly rough and loose, and a large number of structural defects like nonmolten particles, spray angles, large cavities, and cracks were observed scatting on the surface, and all these drawbacks were shown in Figure 2(a). The splash-type particles can be seen in region $B$ and the magnified image in the top right of Figure 2(a) and the large cavities in region A. During thermal spray process, coating materials were heated to the melted or high plastic deformation temperature by the plasma flame and then deposited on the surface of the substrate with the gas flow flying at high velocities. Therefore, APS CoCrAlY coating has the wavy lamellar structure with many interlaces and porosities featured by numerous deformation particles interlacing and overlapping together, as shown in Figure 2(b). However, the large cavities and microcracks among the particles can allow the greater penetration of molten salts or corrosive gases to destroy the coating and severely affect the formation of TGO and, eventually, result in the spallation and failure for the entire coating system.

Figure 3 shows the surface SEM morphology of coating B, coating $\mathrm{C}$, and coating $\mathrm{D}$. It can be seen that the coatings with and without $\mathrm{Al}$ film deposition before and after irradiation present rather different surface character compared with the initial one.

After 20 pulses of irradiation without Al film deposition, as shown in Figure 3(a), the coarse surface was improved to a certain extent. The surface defects, like large particles, spray angles, cavities, and cracks, were partly modified and melted obviously and replaced by the discrete bulged nodules with a glossy and compact appearance, which was the common feature of many HCPEB treated metal materials surface. Therefore, similar structures were observed in experiments with the coatings, coatings $\mathrm{C}$ and $\mathrm{D}$, under $\mathrm{Al}$ deposition and HCPEB irradiation. With Al deposition under 10 pulses of irradiation (Figure 3(b)), the coating surface was remelted entirely and presents two distinct characters, which seemed like "hills (region C) and valleys (region D)," respectively. Simultaneously, a small quantity of cavities were also observed dispersedly in the surface, which was on account of the local sublayer melting and eruption through the surface. As the HCPEB irradiation was further increased to 20 pulses, as shown in Figure 3(c), the discrete bulged "hills" began to agglomerate and merge together to form the larger and connected relatively nodules. Meanwhile, the surface became more smooth and dense, while the cavities and cracks became less and smaller.

Figure 4 reveals further detailed analysis of the surface morphology of coating D. The EDS analysis was carried out on the typical "hills and valleys," which were bulged nodules and sunken pits marked as A and B in Figure 4(a), respectively. The results of point A, as shown in Figure 4(b), 


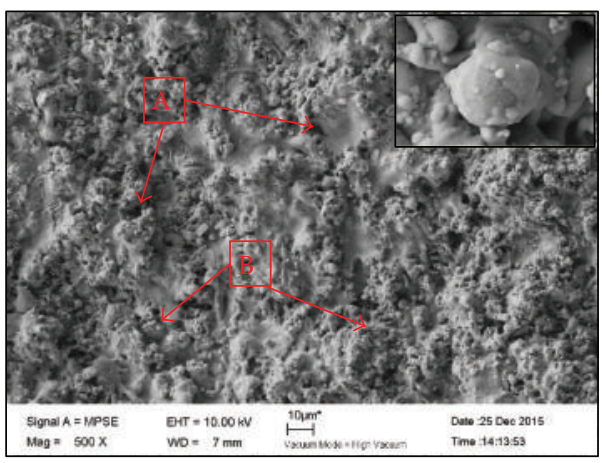

(a)

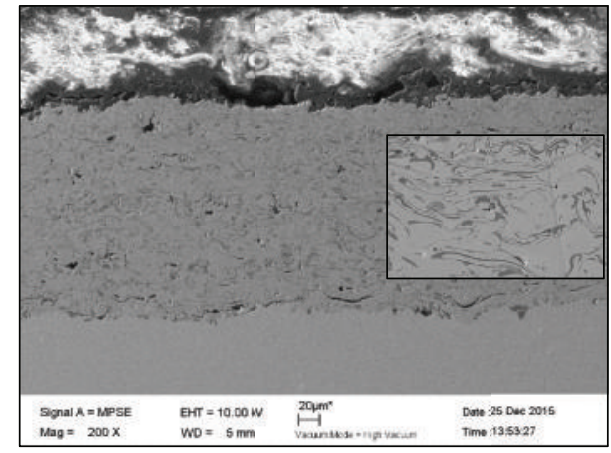

(b)

FIGURE 2: Surface morphology (a) and cross-sectional image (b) of coating A.

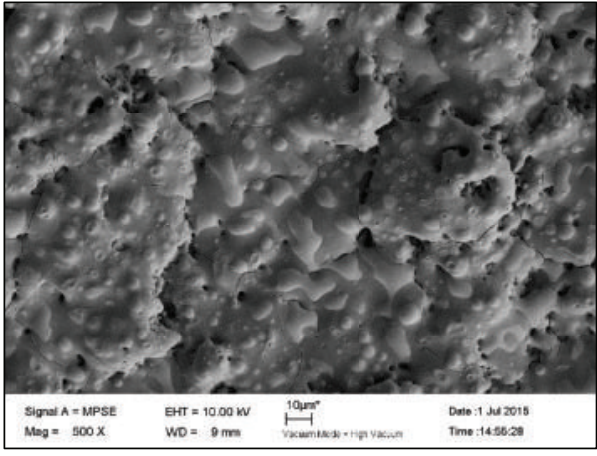

(a)

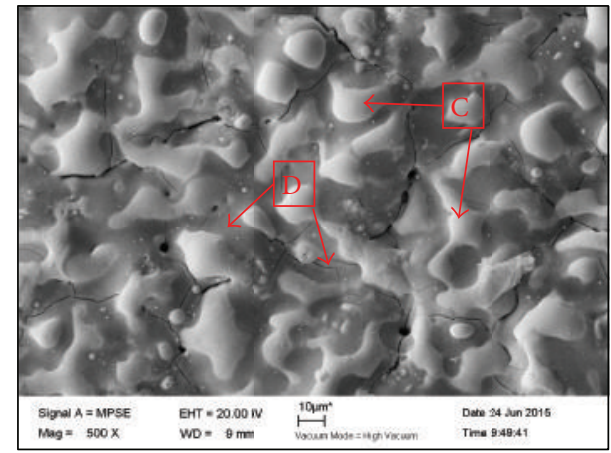

(b)

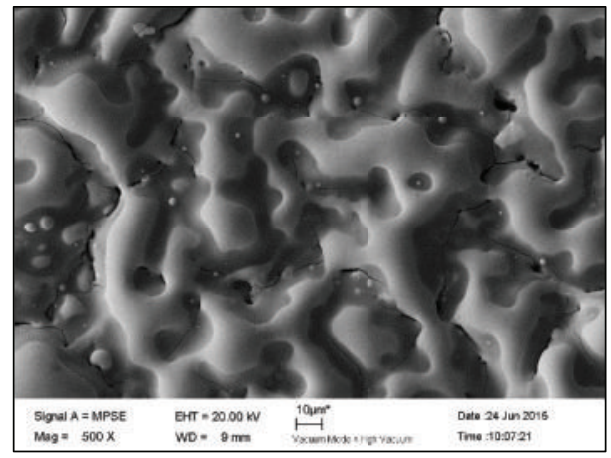

(c)

Figure 3: Surface SEM images of (a) coating B, (b) coating C, and (c) coating D.

clearly reveal that the bulged nodules were composed mainly of the elements $\mathrm{Co}, \mathrm{Cr}$, and $\mathrm{Al}$. However, the point B, "valley," was made up of the elements Al, O, and Y (Figure 4(c)). The higher content of $\mathrm{Al}$ means that the black district might consist of pure $\mathrm{Al}$ and $\mathrm{Al}_{2} \mathrm{O}_{3}$. Besides, the content of element $\mathrm{Y}$ reveals that the selective oxidation of $\mathrm{Y}$ was also available in the surface black oxides, which may form $\mathrm{YAlO}_{3}$ oxides and has an important influence on the growth of TGO and its adherence force $[34,35]$.

Another important aspect is about the vaporization particles which were observed closely adherent to the surface of the smooth bulged nodules from the high-magnification image, as shown in Figure $4(\mathrm{~d})$. Moreover, the diameter of these bubbles was in a range of tens to hundreds of nanometers, and the size of the biggest bubble was about eight hundred nanometers, which was actually called the refined grains and had a significant effect on the elements diffusion and surface roughness. The EDS analysis of the bubble was shown in Figure 4(e). It is obvious that these refined grains were mainly $\gamma$-Co nanoscaled bubbles in which the element Cr was solid dissolved, and they also contained the elements of oxygen and alumina.

The SEM images of the cross-sectional coating D were shown in Figure 5. As shown in Figure 5(a), the crosssectional image was featured by obvious three distinct regions, which were the unaffected CoCrAlY coating in 



(a)

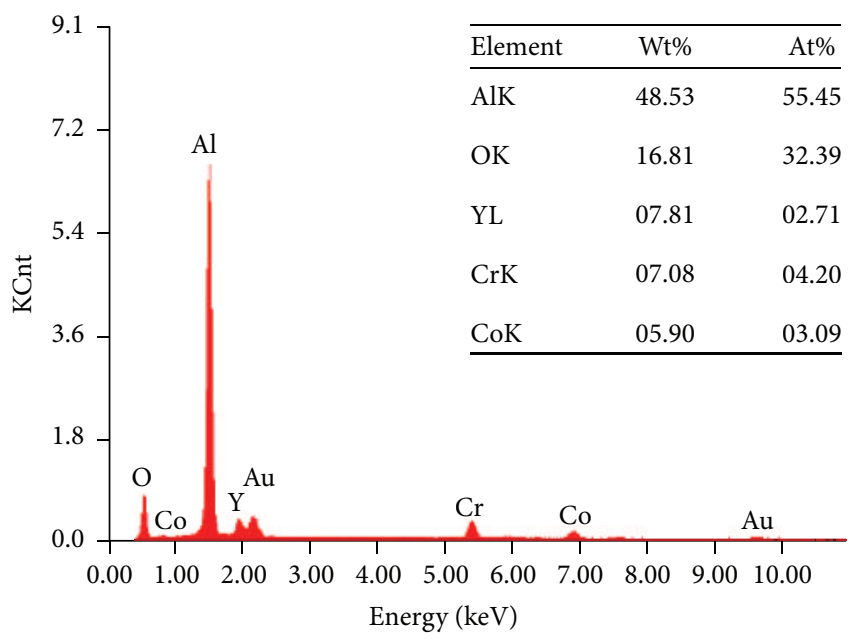

(c)

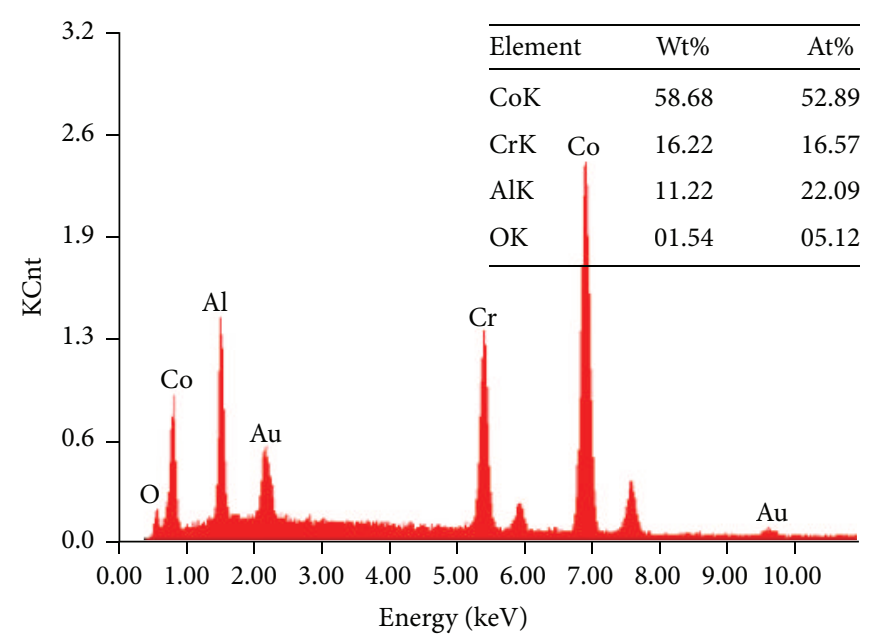

(e)

(b)



(d) nodules; (e) EDS of point C. 


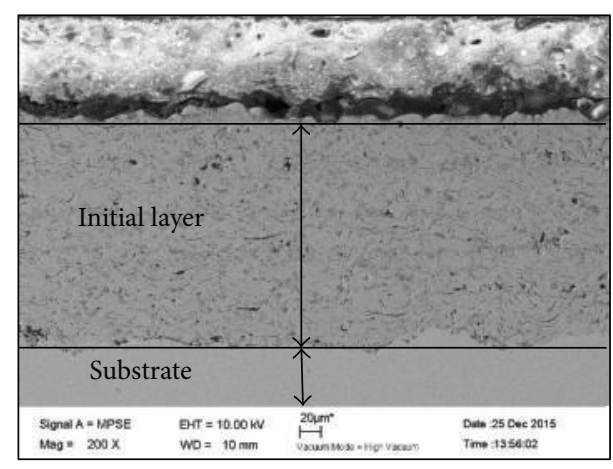

(a)

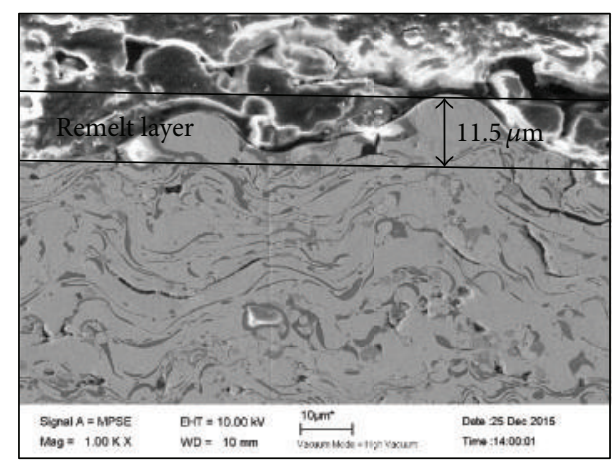

(b)

FIGURE 5: Cross-sectional SEM image of coating D (a) and magnified image (b).

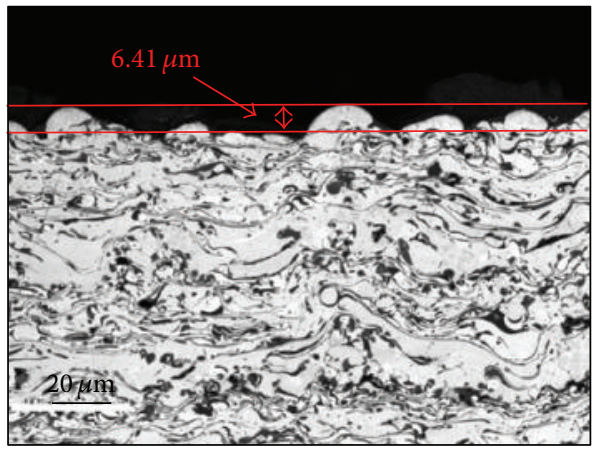

(a)

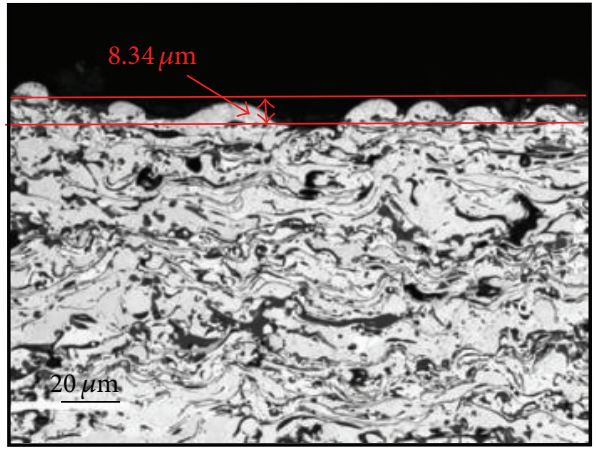

(b)

Figure 6: Cross-sectional magnified LSM images of coating B (a) and coating C (b).

the middle, the substrate at the bottom, and the melted refined region at the upper part. Also, the middle region had the same feature, typical lamellar structures with many interlaces and porosities, as the initial coating (Figure 2(b)). Nevertheless, the upper region was featured by the wavy melted layer with refined structure, as observed in Figure 5 (b). The melted layer of coating $\mathrm{D}$, measuring about $12 \mu \mathrm{m}$, was completely free from embedded oxidation and pores. Homogeneously, the melted layers of coating $\mathrm{B}$ and coating $\mathrm{C}$ were about 6.41 and $8.31 \mu \mathrm{m}$, respectively, as shown in Figure 6. Consequently, it is essential that $\mathrm{Al}$ film deposition and HCPEB irradiation can homogenize the highly nonuniform microstructures which resulted from the As-sprayed CoCrAlY coating.

It can be found that Al film deposition and HCPEB irradiation had very significant effect on the surface modification of the thermally sprayed CoCrAlY coating. As mentioned above, after irradiation, the surface of the coating was characterized by distinct bulged nodules and sunken pits, which could account for the "evaporation" mode. During the electron energy irradiation, the surface melted and the melting sites agglomerated and merged together to form the discontinuously bulged nodules. Besides, as the energy intensified, evaporation of matrix took place and the vapor rapidly removed from the surface and then redeposited to generate the nonscale bubbles eventually $[35,36]$. As for coatings $\mathrm{C}$ and $\mathrm{D}$, the melting and evaporation of surface matrix would be more and faster because of the aluminum film with low melting point, so the bulged nodules on the surface appear larger and continue. Additionally, the nanoscale refined grains adhered to the bulged nodules could effectively increase the rate of aluminum diffusion to generate the uniform and compact TGO and improve the oxidation of thermal barrier coating finally.

\section{Conclusions}

The surface microstructure of as-sprayed CoCrAlY coating, with and without aluminum deposition, before and after HCPEB irradiation, was characterized by means of XRD, SEM, and EDS. The main conclusions could be summarized as follows:

(1) After HCPEB irradiation, Co-based oxides of the initial coating disappeared, while $\mathrm{Al}$ and $\mathrm{Al}_{2} \mathrm{O}_{3}$ phase were detected in the coatings with aluminum deposition, which meant that nanoscaled $\mathrm{Al}$ film could be melted in the surface of CoCrAlY coating.

(2) The initial surface structural defects, large particles, spray angles, cavities, and cracks, were melted and replaced by the successional bulged nodules with glossy and compact appearance under HCPEB 
treatment and $\mathrm{Al}$ deposition. With the increasing HCPEB pulses, the discrete bulged structures began to agglomerate and merge together to form the larger and connected relatively nodules.

(3) The black sunken sites between the bulged nodules were composed mainly of $\mathrm{Al}_{2} \mathrm{O}_{3}$ and $\mathrm{YAlO}_{3}$ oxides, and the melted layer of coatings $\mathrm{B}, \mathrm{C}$, and $\mathrm{D}$ were about $6.41,8.31$, and $12 \mu \mathrm{m}$, respectively.

(4) Abundant nanoscale bubbles (40-850 nm), refined grains, were observed to homogeneously disperse on the irradiated aluminized coating surface on account of evaporation process. The refined structure played a significant role in the resistance of oxidation and corrosion of coating.

\section{Competing Interests}

The authors declare that they have no competing interests.

\section{Acknowledgments}

This work was supported by the National Natural Science Foundation of China (U1333107).

\section{References}

[1] N. P. Padture, M. Gell, and E. H. Jordan, "Thermal barrier coatings for gas-turbine engine applications," Science, vol. 296, no. 5566, pp. 280-284, 2002.

[2] J. R. Nicholls, "Advances in coating design for high-performance gas turbines," MRS Bulletin, vol. 28, no. 9, pp. 659-670, 2003.

[3] M. J. Pomeroy, "Coatings for gas turbine materials and long term stability issues," Materials and Design, vol. 26, no. 3, pp. 223-231, 2005.

[4] A. Cahit, K. Ogawa, A. Turk, and I. Ozdemir, "Thermal shock and cycling behavior of thermal barrier coatings (TBCs) used in gas turbines," in Progress in Gas Turbine Performance, pp. 237260, 2013.

[5] X. Q. Cao, R. Vassen, and D. Stoever, "Ceramic materials for thermal barrier coatings," Journal of the European Ceramic Society, vol. 24, no. 1, pp. 1-10, 2004.

[6] D. Naumenko, V. Shemet, L. Singheiser, and W. J. Quadakkers, "Failure mechanisms of thermal barrier coatings on MCrAlYtype bondcoats associated with the formation of the thermally grown oxide," Journal of Materials Science, vol. 44, no. 7, pp. 1687-1703, 2009.

[7] T. Liang, H. Guo, H. Peng, and S. Gong, "Microstructural evolution of CoCrAlY bond coat on Ni-based superalloy DZ 125 at $1050^{\circ}$ C," Surface \& Coatings Technology, vol. 205, no. 19, pp. 4374-4379, 2011.

[8] K. W. Schlichting, N. P. Padture, E. H. Jordan, and M. Gell, "Failure modes in plasma-sprayed thermal barrier coatings," Materials Science \& Engineering A, vol. 342, no. 1-2, pp. 120-130, 2003.

[9] J. Rösler, M. Bäker, and M. Volgmann, "Stress state and failure mechanisms of thermal barrier coatings: role of creep in thermally grown oxide," Acta Materialia, vol. 49, no. 18, pp. 3659-3670, 2001.
[10] M. Daroonparvar, M. Yajid, M. Y. Noordin, and M. S. Hussain, "The role of nanostructured $\mathrm{Al}_{2} \mathrm{O}_{3}$ layer in reduction of hot corrosion products in normal YSZ layer," Journal of Nanomaterials, vol. 2013, Article ID 251921, 11 pages, 2013.

[11] A. Rabiei and A. G. Evans, "Failure mechanisms associated with the thermally grown oxide in plasma-sprayed thermal barrier coatings," Acta Materialia, vol. 48, no. 15, pp. 3963-3976, 2000.

[12] M. Daroonparvar, M. A. M. Yajid, N. M. Yusof, M. S. Hussain, and H. R. Bakhsheshi-Rad, "Formation of a dense and continuous $\mathrm{Al}_{2} \mathrm{O}_{3}$ layer in nano thermal barrier coating systems for the suppression of spinel growth on the $\mathrm{Al}_{2} \mathrm{O}_{3}$ oxide scale during oxidation," Journal of Alloys and Compounds, vol. 571, pp. 205220, 2013.

[13] E. A. G. Shillington and D. R. Clarke, "Spalling failure of a thermal barrier coating associated with aluminum depletion in the bond-coat," Acta Materialia, vol. 47, no. 4, pp. 1297-1305, 1999.

[14] H. E. Evans and M. P. Taylor, "Diffusion cells and chemical failure of MCrAIY bond coats in thermal-Barrier coating systems," Oxidation of Metals, vol. 55, no. 1, pp. 17-34, 2001.

[15] H. Worch and P. Kofstad, "High temperature corrosion," Crystal Research and Technology, vol. 24, no. 4, p. 378, 1989.

[16] K. Ma and J. M. Schoenung, "Isothermal oxidation behavior of cryomilled NiCrAlY bond coat: homogeneity and growth rate of TGO," Surface \& Coatings Technology, vol. 205, no. 21-22, pp. 5178-5185, 2011.

[17] U. Dragos, M. Gabriela, B. Waltraut, and C. Ioan, "Improvement of the oxidation behaviour of electron beam remelted MCrAlY coatings," Solid State Sciences, vol. 7, no. 4, pp. 459-464, 2005.

[18] I. Ilisz, A. Dombi, K. Mogyorósi, and I. Dékány, "Photocatalytic water treatment with different $\mathrm{TiO}_{2}$ nanoparticles and hydrophilic/hydrophobic layer silicate adsorbents," Colloids and Surfaces A: Physicochemical and Engineering Aspects, vol. 230, no. 1-3, pp. 89-97, 2003.

[19] C. Liu, N. Du, and X. G. Li, "Deposition of Al-Cr alloy coating by electron beam evaporation plating," Journal of Chinese Society for Corrosion and Protection, vol. 23, pp. 257-261, 2003.

[20] X.-L. Niu, L.-J. Wang, D. Sun, J.-L. Dong, and C.-M. Li, "Research on corrosion resistance of Al-Fe-Co-Cr-Ni-Cu highentropy alloy coating by electron beam evaporation plating," Journal of Dalian University of Technology, vol. 53, no. 5, pp. 689694, 2013.

[21] J. H. Wang and H. M. Meng, "Microstructure and corrosion resistance of evaporated $\mathrm{Al}$ and $\mathrm{Al}-\mathrm{Mn}$ films," Ordnance Material Science and Engineering, vol. 31, pp. 1-5, 2008.

[22] R. F. Chen, "Study on the Property of aluminium films prepared by electron beam vapour deposition and magnetron sputtering," Vacuum, vol. 2, pp. 11-15, 2003.

[23] Q. F. Guan, H. Zou, G. T. Zou et al., "Surface nanostructure and amorphous state of a low carbon steel induced by high-current pulsed electron beam," Surface and Coatings Technology, vol. 196, no. 1-3, pp. 145-149, 2005.

[24] X. D. Zhang, S. Z. Hao, T. Grosdidier et al., "Surface modification of light alloys by low-energy high-current pulsed electron beam," Journal of Metallurgy, vol. 2012, Article ID 762125, 10 pages, 2012.

[25] X. Mei, Y. Liu, X. Ma, and Y. Wang, "Structure and performance of YSZ thermal barrier coatings irradiated by high intensity pulsed ion beam," Advanced Materials Research, vol. 538-541, pp. 2377-2381, 2012. 
[26] J. Cai, Q. Guan, S. Yang, S. Yang, Z. Wang, and Z. Han, "Microstructural characterization of modified YSZ thermal barrier coatings by high-current pulsed electron beam," Surface \& Coatings Technology, vol. 254, pp. 187-194, 2014.

[27] S. Hao, L. Zhao, and D. He, "Surface microstructure and high temperature corrosion resistance of arc-sprayed $\mathrm{FeCrAl}$ coating irradiated by high current pulsed electron beam," Nuclear Instruments and Methods in Physics Research Section B: Beam Interactions with Materials and Atoms, vol. 312, pp. 97-103, 2013.

[28] C. Dong, A. Wu, S. Hao et al., "Surface treatment by high current pulsed electron beam," Surface \& Coatings Technology, vol. 163164, pp. 620-624, 2003.

[29] K. Zhang, J. Zou, T. Grosdidier, C. Dong, and D. Yang, "Improved pitting corrosion resistance of AISI 316L stainless steel treated by high current pulsed electron beam," Surface and Coatings Technology, vol. 201, no. 3-4, pp. 1393-1400, 2006.

[30] K. M. Zhang, J. X. Zou, B. Bolle, and T. Grosdidier, "Evolution of residual stress states in surface layers of an AISI D2 steel treated by low energy high current pulsed electron beam," Vacuum, vol. 87, pp. 60-68, 2013.

[31] J. X. Zou, T. Grosdidier, B. Bolle, K. M. Zhang, and C. Dong, "Texture and microstructure at the surface of an AISI D2 steel treated by high current pulsed electron beam," Metallurgical and Materials Transactions A: Physical Metallurgy and Materials Science, vol. 38, no. 9, pp. 2061-2071, 2007.

[32] B. Gao, S. Hao, J. Zou, W. Wu, G. Tu, and C. Dong, "Effect of high current pulsed electron beam treatment on surface microstructure and wear and corrosion resistance of an AZ91HP magnesium alloy," Surface \& Coatings Technology, vol. 201, no. 14, pp. 6297-6303, 2007.

[33] B. Gao, S. Hao, J. Zou et al., "High current pulsed electron beam treatment of AZ31 Mg alloy," Journal of Vacuum Science \& Technology A, vol. 23, no. 6, article 1548, 2005.

[34] A. Gil, D. Naumenko, R. Vassen et al., "Y-rich oxide distribution in plasma sprayed MCrAlY-coatings studied by SEM with a cathodoluminescence detector and Raman spectroscopy," Surface \& Coatings Technology, vol. 204, pp. 531-538, 2009.

[35] J. Cai, Q. Guan, P. Lv, X. Hou, Z. Wang, and Z. Han, "Surface modification of CoCrAIY coating by high-current pulsed electron beam treatment under the 'evaporation' mode," Nuclear Instruments \& Methods in Physics Research B, vol. 337, pp. 9096, 2014.

[36] K. M. Zhang, J. X. Zou, T. Grosdidier et al., "Surface modification of $\mathrm{Ni}$ (50.6 at.\%) Ti by high current pulsed electron beam treatment," Journal of Alloys and Compounds, vol. 434-435, pp. 682-685, 2007. 



\section{Hindawi}

Submit your manuscripts at

http://www.hindawi.com

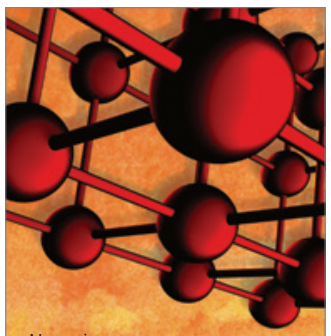

Materials Science and Engineering
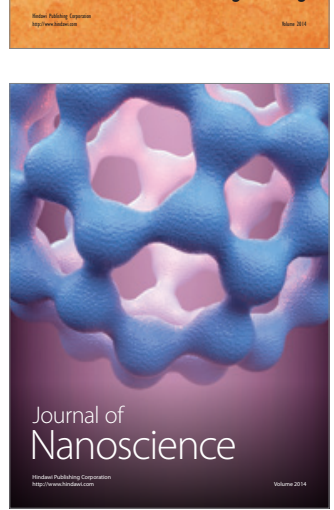
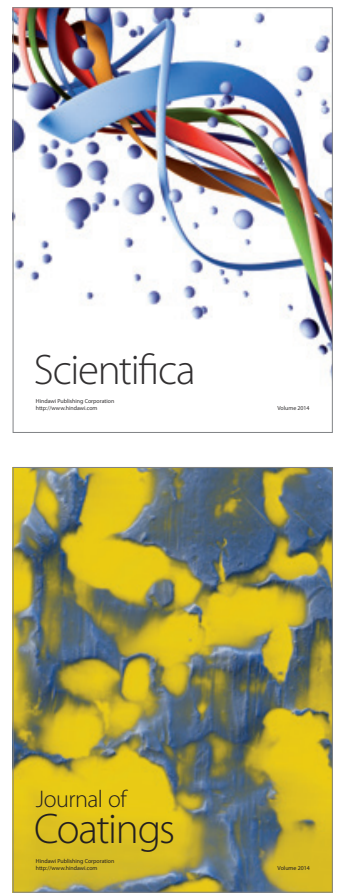
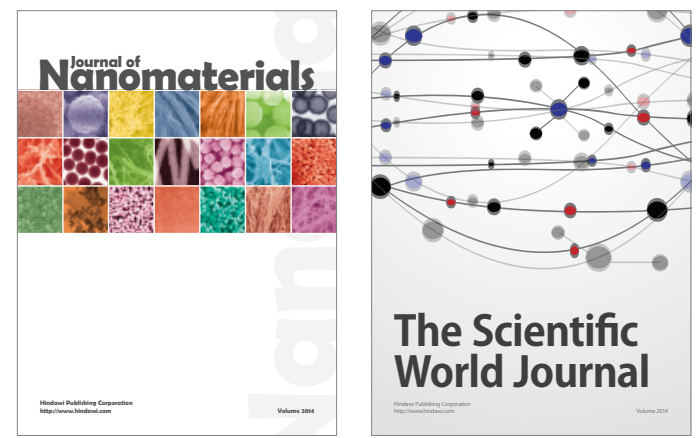

The Scientific World Journal
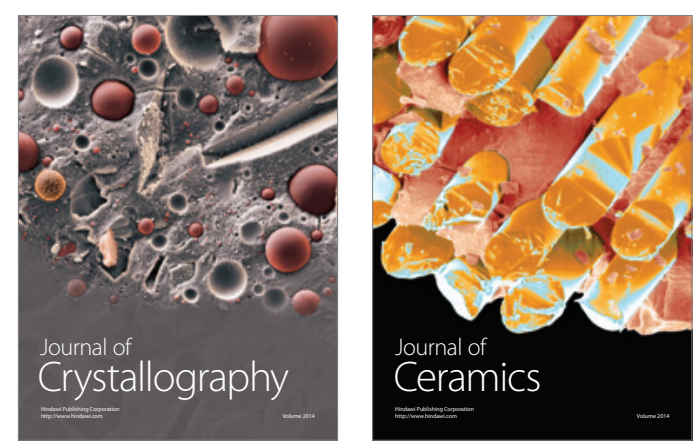
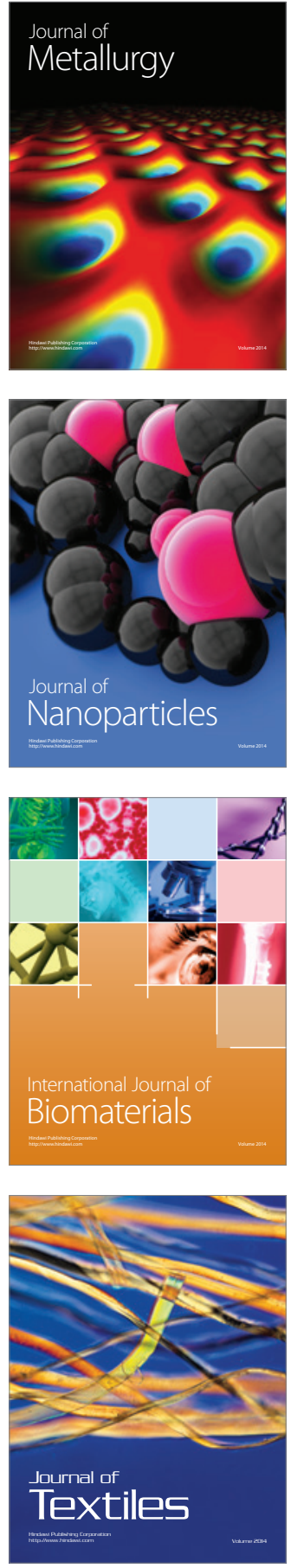